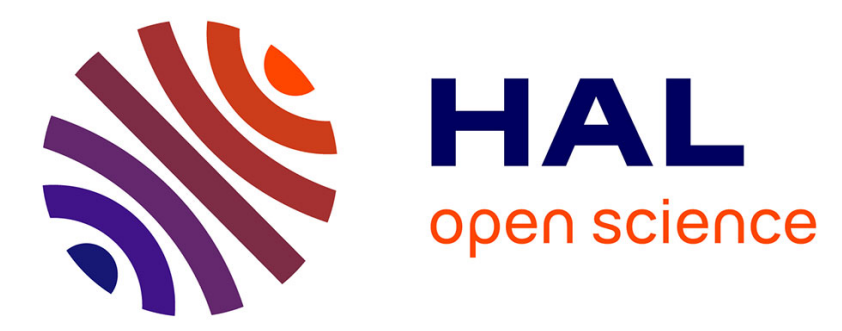

\title{
Step flow growth of Mn5Ge3 films on Ge(111) at room temperature
}

Matthieu Petit, Amine Boussadi, Vasile Heresanu, Alain Ranguis, Lisa Michez

\section{To cite this version:}

Matthieu Petit, Amine Boussadi, Vasile Heresanu, Alain Ranguis, Lisa Michez. Step flow growth of Mn5Ge3 films on Ge(111) at room temperature. Applied Surface Science, 2019, 480, pp.529-536. 10.1016/j.apsusc.2019.01.164 . hal-02061309

\section{HAL Id: hal-02061309 \\ https://hal-amu.archives-ouvertes.fr/hal-02061309}

Submitted on 8 Mar 2019

HAL is a multi-disciplinary open access archive for the deposit and dissemination of scientific research documents, whether they are published or not. The documents may come from teaching and research institutions in France or abroad, or from public or private research centers.
L'archive ouverte pluridisciplinaire HAL, est destinée au dépôt et à la diffusion de documents scientifiques de niveau recherche, publiés ou non, émanant des établissements d'enseignement et de recherche français ou étrangers, des laboratoires publics ou privés. 
Full length article

\title{
Step flow growth of $\mathrm{Mn}_{5} \mathrm{Ge}_{3}$ films on $\mathrm{Ge}(111)$ at room temperature
}

\author{
Matthieu Petit ${ }^{*}$, Amine Boussadi, Vasile Heresanu, Alain Ranguis, Lisa Michez \\ Aix Marseille Univ, CNRS, CINAM, Marseille, France
}

\section{A R T I C L E I N F O}

\section{Keywords:}

Step flow growth

Step meandering

Non-diffusive epitaxy

Molecular beam epitaxy (MBE)

Critical nucleation volume

$\mathrm{Mn}_{5} \mathrm{Ge}_{3}$

Interface

Spintronic

\begin{abstract}
A B S T R A C T
The very first stages of the non-diffusive growth of $\mathrm{Mn}_{5} \mathrm{Ge}_{3}$ thin films on $\mathrm{Ge}(111)$ substrates are characterized by several techniques. $\mathrm{Mn}_{5} \mathrm{Ge}_{3}$ films are grown by molecular beam epitaxy using the co-deposition of $\mathrm{Mn}$ and Ge atoms at room temperature. XRD measurements demonstrate that the thin films are monocrystalline. The evolution of the RHEED intensity during the deposition and the AFM images show a step-flow growth mode. RHEED patterns, combined with TEM images, prove that the lattice mismatch of $3.7 \%$ is accommodated by the formation of an array of interfacial dislocations and by the presence of a residual strain in the thin films. These observations are supported by the numerical calculations of the critical nucleation volumes exhibiting very similar values, in the case of a pseudomorphic growth or in the case of an accommodation of the lattice mismatch by interfacial dislocations. Furthermore, the effect Ge/Mn stoichiometric and Mn-rich fluxes on the surface morphology is examined.
\end{abstract}

\section{Introduction}

Since about 20 years, spintronics has brought significant advances in electronics speed, data storage and power consumption [1,2]. However a key point is still restraining the full blossoming of spintronics: the lack of ferromagnetic materials fully compatible with the mainstream silicon technology, even though a great deal of efforts has been devoted to the development of semiconductors exhibiting magnetic properties. Two families of magnetic semiconductors exist. The first one is the concentrated magnetic semiconductors (CMS), based on rare-Earth chalcogenides. But the development of these compounds is hindered by their relatively low Curie temperature $\left(\mathrm{T}_{C}\right)$ (the highest value reported is $117 \mathrm{~K}$ for EuO) and notorious difficulty in materials synthesis [3,4]. The second family is the diluted magnetic semiconductors (DMS) one. These materials are extensively studied, in particular the $(\mathrm{Ga}, \mathrm{Mn})$ As alloys with $\mathrm{T}_{C}$ remaining below $200 \mathrm{~K}$ and the $\mathrm{Ge}_{1-x} \mathrm{Mn}_{x}$ with $\mathrm{T}_{C}$ around $150 \mathrm{~K}[5,6,7,8,9]$.

In this context, $\mathrm{Mn}_{5} \mathrm{Ge}_{3}$ has attracted a great deal of interest, since the demonstration of its epitaxial growth as a thin film on $\mathrm{Ge}(111)$ substrates with an atomically sharp interface, although the lattice mismatch is $3.7 \%$ [10]. That was the sign of the potential of $\mathrm{Mn}_{5} \mathrm{Ge}_{3}$ as a ferromagnetic electrode suitable for the $\mathrm{Si} / \mathrm{Ge}$ technology, in particular since the interfaces play a key role in spintronics [11]. $\mathrm{Mn}_{5} \mathrm{Ge}_{3}$ is a ferromagnetic metal with a $\mathrm{T}_{C}$ of $296 \mathrm{~K}$ and a hexagonal crystal structure (space group $\mathrm{P}_{3} / \mathrm{mcm}$ ) [12]. The $\mathrm{T}_{C}$ can be increased up to $450 \mathrm{~K}$ by introducing carbon atoms in the octahedral interstitial site of the lattice $[13,14]$. The spin polarization was measured at $\mathrm{P}=15 \pm 5 \%$ and the magnetic and electrical properties of the $\mathrm{Mn}_{5} \mathrm{Ge}_{3}$ and $\mathrm{Mn}_{5} \mathrm{Ge}_{3} \mathrm{C}_{x}$ alloys have been extensively investigated [15,16,17].

Regarding the growth processes, two methods can be employed to grow $\mathrm{Mn}_{5} \mathrm{Ge}_{3}$ thin films on $\mathrm{Ge}(111)$ substrates with very good structural properties, especially without threading dislocations despite the significant lattice mismatch. The solid phase epitaxy (SPE) was the first method used by Zeng et al., and it is the commonly used one [10]. It consists on the deposition of manganese on $\mathrm{Ge}(111)$ at room temperature, followed by an annealing at $700-720 \mathrm{~K}$. The $\mathrm{Mn}_{5} \mathrm{Ge}_{3}$ phase is formed thanks to the diffusion process and the epitaxial stabilization offered by the three order symmetry of the Ge(111) surface. The main drawback of this growth process is the annealing. This step is an impairment in the control of the interface $\mathrm{Mn}_{5} \mathrm{Ge}_{3} / \mathrm{Ge}$. On one hand, it entails a diffusion profile of $\mathrm{Mn}$ at the $\mathrm{Mn}_{5} \mathrm{Ge}_{3} / \mathrm{Ge}$ interface, affecting the electrical properties which is detrimental to electrical spin injection. On the other hand, such an annealing step prevents the tailoring of the $\mathrm{Mn}_{5} \mathrm{Ge}_{3} / \mathrm{Ge}$ Schottky contact by, for instance, the insertion of heavy doped Ge layers at the interface, needed to maximize the spin injection through the Schottky barrier existing at the $\mathrm{Mn}_{5} \mathrm{Ge}_{3} / \mathrm{Ge}$ contact [18]. To overcome these issues, our team developed a non-diffusive growth method by molecular beam epitaxy (MBE): it consists on the formation of the $\mathrm{Mn}_{5} \mathrm{Ge}_{3}$ thin films by stoichiometric co-deposition of both $\mathrm{Mn}$ and $\mathrm{Ge}$ on $\mathrm{Ge}(111)$ at room temperature. The formation of $\mathrm{Mn}_{5} \mathrm{Ge}_{3}$ film is favourable thanks to the low interface energy between $\mathrm{Ge}(111)$ and $\mathrm{Mn}_{5} \mathrm{Ge}_{3}$, and to its low enthalpy of formation compare to the other

\footnotetext{
* Corresponding author.

E-mail address: matthieu.petit@univ-amu.fr (M. Petit).
} 
phases of the Mn-Ge phase diagram [7,19,20]. The growth at room temperature allows to create well defined interfaces on a structural point of view but especially on an electrical account [21,22].

Using the co-deposition process, we focused on the first step of the $\mathrm{Mn}_{5} \mathrm{Ge}_{3}$ thin film growth on $\mathrm{Ge}(111)$ and on the interface between these two materials. In-situ RHEED intensity monitoring and ex-situ atomic force microscopy (AFM) images, taken at different deposition times and for two different ratios of the respective $\mathrm{Mn}$ and Ge fluxes, are combined to describe the formation and the morphology of the first nanometres of the $\mathrm{Mn}_{5} \mathrm{Ge}_{3}$ films. Transmission electron microscopy (TEM) pictures of the interface revealed the atomic organization. We compared these experimental results and a numerical calculation of the critical nucleation volume $\mathrm{V}_{C}$ to determine whether the accommodation of the lattice mismatch involves a pseudomorphic growth or interfacial dislocations.

\section{Experimental details}

The growth method of the $\mathrm{Mn}_{5} \mathrm{Ge}_{3}$ thin films was described in an earlier paper [21]. The samples are synthesised by MBE in a ultra-vacuum chamber with a base pressure of $2.7 \times 10^{-8} \mathrm{~Pa}$. On-axis oriented Ge(111) substrates are used and are chemically cleaned before introduction into the MBE chamber. The substrate RMS roughness measured by AFM prior to the growth is $0.52 \mathrm{~nm}$, on $5 \times 5 \mu \mathrm{m}^{-2}$ field. The $\mathrm{Ge}$ and $\mathrm{Mn}$ flows of the Knudsen cells were carefully calibrated and lead to a $\mathrm{Mn}_{5} \mathrm{Ge}_{3}$ growth rate of $1 \mathrm{~nm} \cdot \mathrm{min}^{-1}$. The growth can be monitored in real time by RHEED (acceleration voltage: $30 \mathrm{kV}$ ) and a CCD camera fixed above the fluorescent screen allows to record the evolution of the RHEED patterns versus time of deposition. Indeed, the $\mathrm{Mn}_{5} \mathrm{Ge}_{3}$ films exhibit an easily identifiable $(\sqrt{3} \times \sqrt{3}) \mathrm{R} 30^{\circ}$ reconstruction RHEED pattern (see for instance inset of Fig. 2 or Fig. 1e)-f) of ref. [23]). For some of the samples, the growth was interrupted in order to image by AFM or TEM the surface of the samples at the corresponding time (i.e at an equivalent deposited $\mathrm{Mn}_{5} \mathrm{Ge}_{3}$ thickness $d$ of $0.4,3.6$ and $20 \mathrm{~nm}$ for AFM and $20 \mathrm{~nm}$ for TEM) or to perform XRD analysis (at $d=20 \mathrm{~nm}$ ). For the AFM images, we used a Nanoscope IIIA Multimode (Digital instruments) equipped with a $10 \times 10 \times 2.5 \mu \mathrm{m}$ scanner. The images were recorded in tapping mode at room temperature using silicon probes (HQ:NSC15/AL BS, Mikromasch). The curvature radius of the silicon tips was about $8 \mathrm{~nm}$ (supplier specifications) and the vertical resolution is $0.4 \AA$. The AFM images were analyzed using the Gwyddion software [24]. TEM investigations were performed at an accelerating voltage of $300 \mathrm{kV}$ on a JEOL JEM-3010 instrument with a spatial resolution of $1.7 \AA$ A . Cross-section samples were prepared with a precision ion polishing system (PIPS). XRD measurements were done on a $\theta-\theta$ diffractometer, Panalytical X'Pert Pro MPD (for quantitative analysis) and a on a rotating anode Rigaku RU200BH equipped with a Mar345 detector (mainly for qualitative observations). In both cases the $\mathrm{Cu}$ $(\mathrm{K} \alpha 1+\mathrm{K} \alpha 2)$ radiation was used $(\lambda=0.1542 \mathrm{~nm})$. X'Pert HighScore software was used for peak analysis.

\section{Calculation}

The aim of the following calculation is to obtain a trend whether the lattice mismatch between $\mathrm{Mn}_{5} \mathrm{Ge}_{3}$ and $\mathrm{Ge}(111)$ gives rise to a pseudomorphic growth or to an array of interfacial dislocations, since no other accommodation mechanisms are observed. The first stages of an epitaxial growth can be assimilated to a condensation process provided that the chemical potential of the gas phase is higher than the one of the solid phase. Thermodynamics foretells a critical volume $V_{C}$ of the nuclei deposited on the surface above which they are stable. $V_{C}$ is calculated by maximizing the nucleation free enthalpy $\Delta G(V)$ of a deposited material on a substrate $[25,26,27,28] . \Delta G(V)$ can be written as follows:

$\Delta G(V)=\left(E_{e l}-\Delta \mu\right) V+\left(\gamma_{\text {interf }}-\gamma_{\text {sub }}\right) S_{\text {interf }}+\gamma_{\text {dep }} S_{\text {dep }}$

$E_{e l}$ is the elastic energy per unit of volume stored in the deposit, $\Delta \mu$ is the chemical potential difference per unit of volume of the deposit, between the gas phase and the solid phase. $\gamma_{\text {sub }}, \gamma_{\text {dep }}, \gamma_{\text {interf }}$ are the surface energies of the substrate, the deposit and the interface between the substrate and the deposit, respectively. $S_{\text {dep }}$ is the free surface of the deposit and $S_{\text {interf }}$, the area of the interface between the substrate and the deposit. From our previous work, the growth of $\mathrm{Mn}_{5} \mathrm{Ge}_{3}$ films is two dimensional, hence we limited the calculation of the critical nucleation volume $\mathrm{V}_{C}$ to the bidimensional cases [21]. To simplify the problem, the nuclei are described by a cylindrical shape with a diameter $d$ and a height $h$ equal to one monolayer. Thus $\Delta G(V)$ can be rewritten:

$\frac{\Delta G(V)}{\Delta \mu}=\left(\frac{E_{e l}}{\Delta \mu}-1\right) \frac{\pi d^{2}}{4} h+\frac{\gamma_{d e p}}{\Delta \mu}\left(\pi d h+\frac{\pi d^{2}}{4}\left(1+a_{1}\right)\right)$

where $\left.a_{1}=\left(\gamma_{\text {interf }}-\gamma_{\text {sub }}\right) / \gamma_{\text {dep }}\right) . \Delta G(V) / \Delta \mu$ exhibits a maximum for a critical diameter $d_{c}$ :

$d_{c}=\frac{2 \gamma_{d e p} / \Delta \mu}{\left(1-\frac{E_{e l}}{\Delta \mu}-\frac{\gamma_{d e p}}{h \Delta \mu}\left(1+a_{1}\right)\right)}$

corresponding to a critical volume $V_{c}=\frac{\pi d_{c}^{2}}{4} h$.

Two cases are foreseeable: a pseudomorphic growth mode of the deposit on the substrate meaning that the deposit is elastically strained on the substrate (corresponding critical volume $V_{c}^{e l}$ ) or a growth mode where the lattice mismatch is accommodated by an array of interfacial dislocations (corresponding critical volume $V_{c}^{\text {dis }}$ ). In the first case, $E_{e l}$ can be express as $E_{\text {el }}=Y_{\text {dep }} /\left(1-v_{\text {dep }}\right) R m^{2}$, with $Y_{\text {dep }}$ and $\nu_{\text {dep }}$ the Young modulus and the Poisson coefficient of the deposited materials. $m$ is the lattice mismatch between the deposit and the substrate: $m=\left(a_{\text {dep }}-a_{\text {sub }}\right) / a_{\text {sub }} . R$ takes into account the fact that the nuclei are not of infinite size in the lateral dimensions, which entails a partial relaxation, through free surfaces, of the stored elastic energy: $R=1-e^{-2 k d / h}$. For a cylindrical shape, $k=0.073$ and $R$ can be sensibly approximated to 1 [29]. In the second case, $E_{e l}$ is equal to zero and the energetic cost of the formation of the dislocations has to be introduced in Eq. (3). The element $a_{1}$ becomes $a_{1}^{\prime}=a_{1}+a_{\text {dis }}$ where [28]:

$a_{d i s}=m b \frac{Y_{\text {dep }} Y_{\text {sub }}}{Y_{\text {dep }}\left(1+v_{\text {sub }}\right)+Y_{\text {sub }}\left(1+v_{\text {dep }}\right)}\left(\frac{1}{4 \pi} \ln \frac{h}{b}+0.1\right)$

$Y_{\text {sub }}$ and $\nu_{\text {sub }}$ are the Young modulus and the Poisson coefficient of the substrate, and $b$ is the Burger vector of the dislocations. The two different values of the critical nucleation volumes $V_{c}^{\text {el }}$ and $V_{c}^{\text {dis }}$ can be compared in order to determine which mechanism is more favourable for the growth of $\mathrm{Mn}_{5} \mathrm{Ge}_{3}$ on $\mathrm{Ge}(111)$.

\section{Results and discussion}

\subsection{Numerical results on the critical nucleation volumes}

The numerical values of the experimental parameters needed to perform the calculations of the critical nucleation volumes $V_{c}^{\text {el }}$ and $V_{c}^{\text {dis }}$ are summarised in Table $1 . \Delta \mu$ was fixed at $0.5 \mathrm{eV}$. This value was chosen using ref. [30] where the authors demonstrate that a value of $\frac{\Delta \mu}{k_{B} T}$ around 19 corresponds to the limit between a growth mode prone to kinetic roughening and a layer-by-layer one.

Table 1

Experimental parameters needed to perform the calculations of the critical nucleation volumes $V_{c}^{e l}$ and $V_{c}^{d i s}$

\begin{tabular}{lccc}
\hline & $\mathrm{Ge}$ & $\mathrm{Mn}_{5} \mathrm{Ge}_{3}$ & Interface \\
\hline Young modulus $Y(\mathrm{GPa})$ & $103[31,32,33]$ & $110[34]$ & \\
Poisson's ratio $\nu$ & $0.26[31,32,33]$ & & \\
Surface/interface energy $\left(\mathrm{J} \cdot \mathrm{m}^{2}\right)$ & $1.06[35]$ & & $0.53[7,19]$ \\
Burger's vector $b(\AA)$ & & $7.18[36]$ & \\
Monolayer height $h(\AA)$ & & $5[37]$ &
\end{tabular}



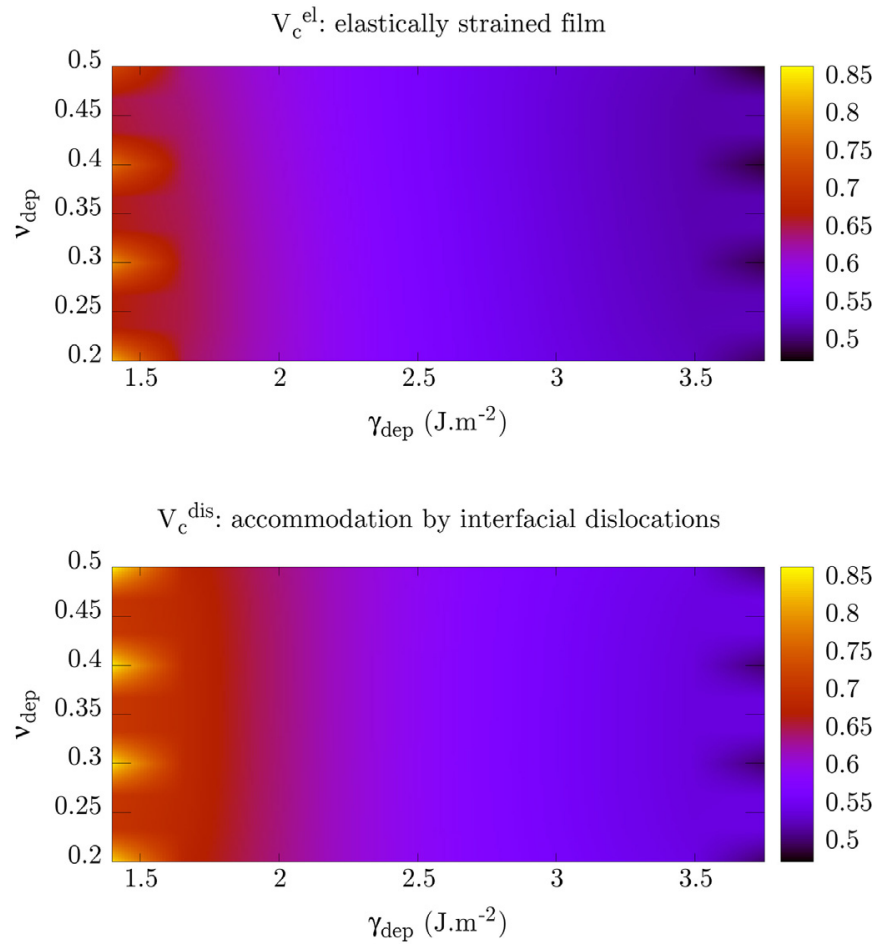

Fig. 1. Maps of the critical volume of nucleation as a function of the surface energy and of the Poisson's ratio of the $\mathrm{Mn}_{5} \mathrm{Ge}_{3}$ deposit. Top figure: accommodation of the lattice mismatch between the $\mathrm{Mn}_{5} \mathrm{Ge}_{3}$ film and the $\mathrm{Ge}(111)$ substrate via an elastically strained film $\left(V_{c}^{e l}\right)$. Bottom figure: accommodation via an array of interfacial dislocations $\left(V_{c}^{d i s}\right)$. The color scale on the right side is in $\mathrm{nm}^{3}$.

Two parameters remain unknown: the surface energy $\gamma_{\text {dep }}$ of the $\mathrm{Mn}_{5} \mathrm{Ge}_{3}$ film and the Poisson's ratio $\nu_{\text {dep }}$ of $\mathrm{Mn}_{5} \mathrm{Ge}_{3}$. We chose to draw the maps of $V_{c}^{e l}$ and $V_{c}^{\text {dis }}$ versus $\gamma_{\text {dep }}$ and $\nu_{\text {dep }}$. The range of values for the $\gamma_{\text {dep }}$ axis was determined knowing that the $\mathrm{Mn}_{5} \mathrm{Ge}_{3}$ surface is $\mathrm{Mn}$ rich terminated [38]. According to the literature, the Mn surface energy exhibits values from 1.5 to $3.75 \mathrm{~J} \cdot \mathrm{m}^{-2}$ [39,40,41,42]. Regarding the abscissa axis, the range [0.20-0.50] corresponds to typical Poisson's coefficients observed for several families of materials [43]. The two maps are presented on Fig. 1.

The two maps are very similar in terms of values reached by the critical volumes and in terms of distribution of these values as a function of $\gamma_{\text {dep }}$ and $\nu_{\text {dep }}$. From an epitaxial growth point of view, it means that the two mechanisms of accommodation of the lattice mismatch could be simultaneously observed during the growth of the $\mathrm{Mn}_{5} \mathrm{Ge}_{3}$ film on $\mathrm{Ge}(111)$, as confirmed by the following experimental results.

\subsection{Mismatch accommodation}

The deposition of the $\mathrm{Mn}_{5} \mathrm{Ge}_{3}$ thin films are followed in situ by RHEED. The intensity of the specular streak is recorded along with the distance between the 00 and 01 streaks, which is converted into the value of the lattice parameter. The evolution of the intensity is displayed on Fig. 2.

As soon as the co-deposition of Ge and Mn started, the intensity decreased significantly. Although the intensity dropped, the RHEED streak patterns were still detected, allowing the measurement of the lattice parameter all along the co-deposition. From 0 to a thickness of $4.0 \mathrm{~nm}$, the lattice evolved from $(0.400 \pm 0.005) \mathrm{nm}$ ( $\mathrm{Ge}(111)$ surface) to $(0.420 \pm 0.050) \mathrm{nm}$. After a deposition of $4.0 \mathrm{~nm}$, the lattice value stabilised around $(0.418 \pm 0.025) \mathrm{nm}$. This indicates that a slight tensile strain $(0.7 \%)$ remains in the $\mathrm{Mn}_{5} \mathrm{Ge}_{3}$ film since the lattice bulk value of $\mathrm{Mn}_{5} \mathrm{Ge}_{3}$ is $0.415 \mathrm{~nm}$. The fact that the RHEED pattern of

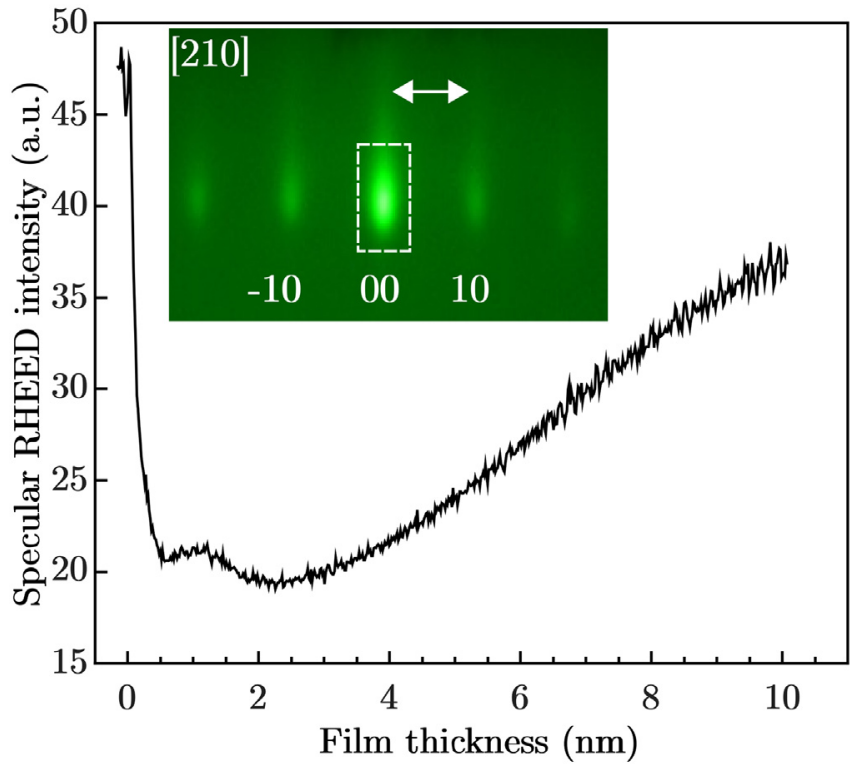

Fig. 2. Typical evolution of the intensity of the 00 streak of the RHEED pattern taken along the azimuth [210] of the typical $\mathrm{Mn}_{5} \mathrm{Ge}_{3}(001)(\sqrt{3} \times \sqrt{3}) \mathrm{R} 30^{\circ}$ surface. The white dotted rectangle on the pattern indicates the area used to record the intensity. The white double arrow shows the distance between the streaks used to calculate the value of the lattice parameter of the $\mathrm{Mn}_{5} \mathrm{Ge}_{3}(001)$ plan.

$\mathrm{Mn}_{5} \mathrm{Ge}_{3}$ was quickly obtained, is consistent with the small values of the critical volumes of nucleation calculated on Fig. 1. The crystallinity of the $20 \mathrm{~nm}$ thick $\mathrm{Mn}_{5} \mathrm{Ge}_{3} / \mathrm{Ge}(111)$ thin film was examined by XRD, in order to get information regarding the c-axis of the $\mathrm{Mn}_{5} \mathrm{Ge}_{3}$ lattice. The XRD patterns are displayed on Fig. 3.

The 2D-XRD image of Fig. 3a) is consistent with a single crystal $\mathrm{Mn}_{5} \mathrm{Ge}_{3}$ layer, the position of the diffraction spots being in good agreement with the reflections (as indicated in the image) mentioned in the reference file of $\mathrm{Mn}_{5} \mathrm{Ge}_{3}$ (ICSD-01-089-4887). On Fig. 3b), the $\theta-\theta$ measurements show that only the diffraction peaks corresponding to the 002 and 004 reflections were detected. This indicates a monocrystalline $\mathrm{Mn}_{5} \mathrm{Ge}_{3}$ thin film with the c-axis normal to the surface of the substrate, in agreement with the 2D-XRD data. Fitting these XRD data with the profile fitting software X'Pert HighScore, the interplanar distance $\mathrm{d}_{001}$ is measured at $(0.5035 \pm 0.0001) \mathrm{nm}$. This value indicates a compressive strain of $-(0.5 \pm 0.1) \%$ of the $\mathrm{Mn}_{5} \mathrm{Ge}_{3}$ lattice, along the c-axis. The full width at half maximum (FWHM) of the diffraction peaks of $\mathrm{Mn}_{5} \mathrm{Ge}_{3}$ is $0.51^{\circ}$ (the instrumental width evaluated with the 111 reflection of the Ge substrate is $0.03^{\circ}$ ). Considering that the broadening of the diffraction peaks arose from the low thickness of the film, we apply the Scherrer equation to obtain a minimal thickness value of the $\mathrm{Mn}_{5} \mathrm{Ge}_{3}$ film of $17 \mathrm{~nm}$, which is consistent with the $20 \mathrm{~nm}$ thick film planned with the deposition fluxes [44]. The values of strain obtained with the RHEED and XRD characterizations have to be compared to the 3.7\% lattice mismatch between $\mathrm{Ge}(111)$ and the bulk $\mathrm{Mn}_{5} \mathrm{Ge}_{3}$ : the $\mathrm{Mn}_{5} \mathrm{Ge}_{3}$ thin film is almost relaxed. To go further in the description of the $\mathrm{Mn}_{5} \mathrm{Ge}_{3} / \mathrm{Ge}(111)$ interface, cross-sectional TEM images of the interface have been taken (Fig. 4).

A periodical intensity contrast can be observed on the top image, with an occurrence every $16 \mathrm{~nm}$ along the [010] direction of the $\mathrm{Mn}_{5} \mathrm{Ge}_{3}$ film. It corresponds to an array of dislocations spaced of a distance corresponding to 24 unit cells. This arrangement entails a relaxation of the thin film with a slight remaining tensile strain of $0.65 \%$, in good agreement with the RHEED measurements. The bottom image shows an enlargement focussed on a dislocation: a stacking fault can be seen at the centre of the white dotted ellipse. Interfacial dislocations along the $\mathrm{Ge}(111) / \mathrm{Mn}_{5} \mathrm{Ge}_{3}$ interface have also been observed in the 
a)
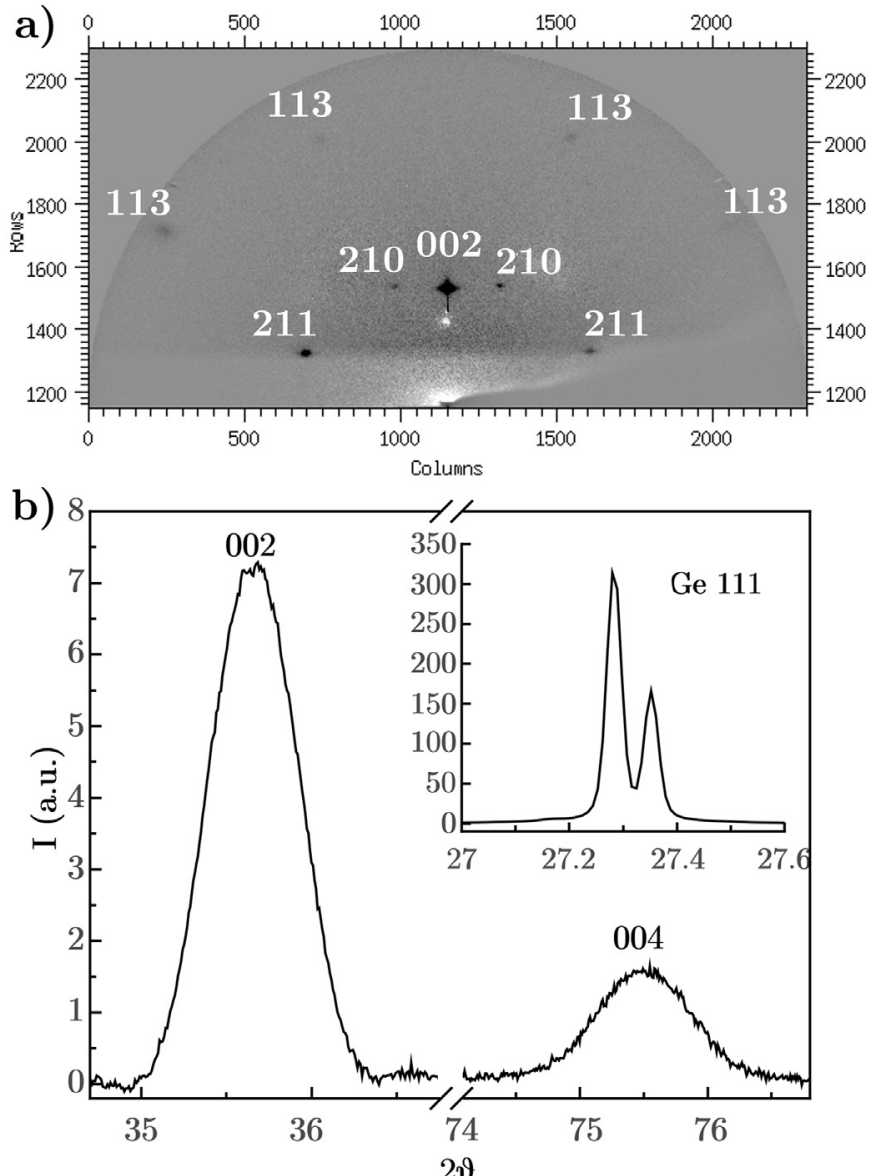

$2 \vartheta$

Fig. 3. a) $2 \mathrm{D}-\mathrm{XRD}$ pattern of a $20 \mathrm{~nm}$ thick $\mathrm{Mn}_{5} \mathrm{Ge}_{3}$ thin film. The signal of the Ge substrate has been subtracted. The angle between the incident X-ray beam and the sample surface ( $\omega$ angle) varied from 15 to $20^{\circ}$ during the acquisition. b) XRD pattern of the $20 \mathrm{~nm}$ thick $\mathrm{Mn}_{5} \mathrm{Ge}_{3}$ thin film. The diffraction peaks correspond to the 002 and 004 reflections of $\mathrm{Mn}_{5} \mathrm{Ge}_{3}$. The insert displays the peaks corresponding to the 111 reflection of Ge substrate $\left(\mathrm{CuK}_{\alpha 1}, \mathrm{CuK}_{\alpha 2}\right)$, the Ge signal was attenuated by a factor 85 , in order to avoid the damage of the detector.

case of the SPE growth mode by several teams, with the same periodicity $[45,46]$. Bringing together the results from the RHEED and XRD patterns, and the TEM images, the lattice mismatch between $\mathrm{Mn}_{5} \mathrm{Ge}_{3}$ and Ge(111) seems to be accommodated by two mechanisms: a slightly strained layer as shown by the residual stress calculated with the RHEED streaks shift and the XRD measurements, and the interfacial dislocations observed on the TEM images. The previous numerical calculations are consistent with these experimental observations.

\subsection{Step-flow growth mode and surface morphology}

The in situ monitoring of the specular RHEED intensity, as already shown on Fig. 2, gives information on the growth mode and the surface roughness of the $\mathrm{Mn}_{5} \mathrm{Ge}_{3}$ thin films. Two monitoring have been carried out, according to the respective $\mathrm{Mn}$ and Ge fluxes: the first monitoring has been done with a co-deposition of $\mathrm{Mn}$ and $\mathrm{Ge}$ in the stoichiometric ratio, the second one in Mn-rich condition ( $\mathrm{Mn} / \mathrm{Ge}$ ratio equal to 1.9). The evolution of the specular intensities is the same for both growth conditions. The persistent streaky RHEED patterns along with the quickly damped intensities and one discernible oscillation are commonly attributed to a one-dimensional step-flow growth mode $[47,48]$. This implies a quite high surface mobility of the adatoms. The difference between the stoichiometric and Mn-rich conditions lies in the background intensity, which is higher in the case of the Mn-rich

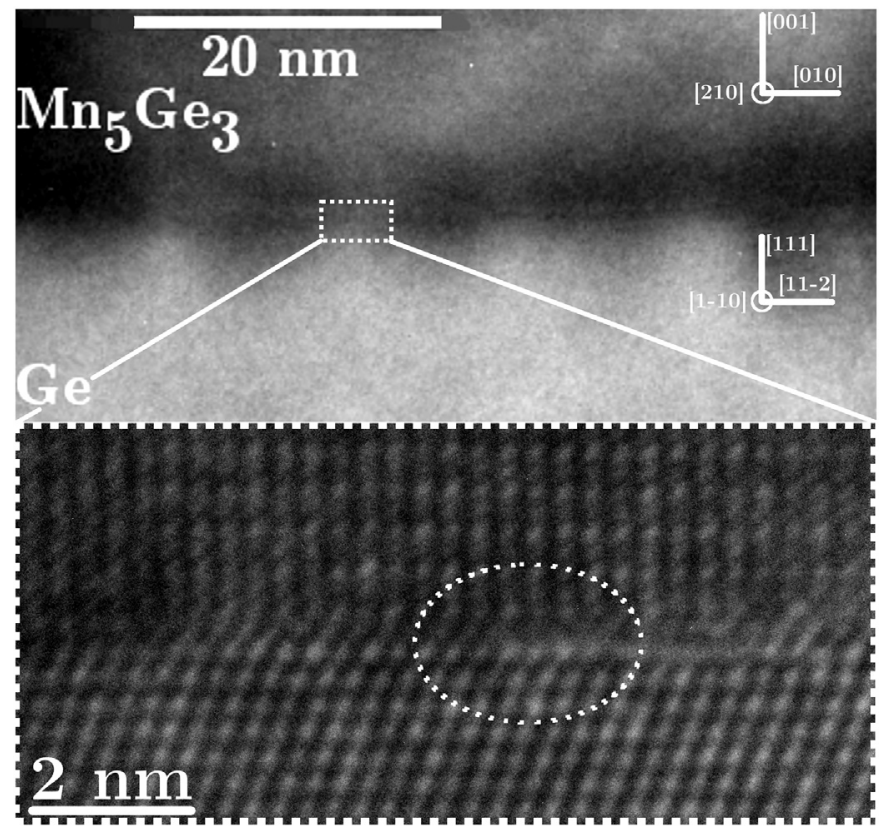

Fig. 4. Top image: TEM image of a cross section of $\mathrm{Mn}_{5} \mathrm{Ge}_{3}$ film. The periodical contrast of the intensity at the interface indicates the presence of interfacial dislocations every $16 \mathrm{~nm}$. Bottom image: zoom on a dislocation from the top image.

growth. This can be linked to a bigger surface roughness of the thin film, maybe due to the increase of $\mathrm{Mn}$ adatoms. To confirm these statements related to the RHEED observations, AFM images have been taken at different film thicknesses on as-grown samples. Panels a) and g) in Fig. 5 (resp. d) and h)) show the surface morphology of 0.4 and $20 \mathrm{~nm}$ thick $\mathrm{Mn}_{5} \mathrm{Ge}_{3}$ films grown with stoichiometric (resp. Mn-rich) condition.

On Fig. 5a) and g), corresponding to thin films grown under stoichiometric fluxes, terraces with non-uniform length are clearly visible, and the surface morphology exhibits a slight fingers like pattern. This confirms the step-flow growth mode and points out a meandering instability which may arise from different surface diffusion lengths and an asymmetric attachment to the steps of the Ge and $\mathrm{Mn}$ adatoms as described in refs. [49] and [50] and observed in the case of plasma-assisted MBE growth of GaN layers on different kinds of GaN substrates [51]. The height and the maximum length of these terraces have been measured on a $2 \times 2 \mu \mathrm{m}^{2}$ scans and were evaluated to $(0.40 \pm 0.08)$ $\mathrm{nm}$ and $(140 \pm 10) \mathrm{nm}$, respectively (cf. AFM profile Fig. 5b)). The terrace height is closed to the thickness of one monolayer of $\mathrm{Mn}_{5} \mathrm{Ge}_{3}$ along the c-axis of the lattice: $0.5 \mathrm{~nm}$ [37]. The RMS roughness for both films thicknesses is $0.76 \mathrm{~nm}$. Hexagonal pits are present for both thicknesses (No pits are observed on the Ge(111) substrates surfaces before the growth). The hexagonal shape is attributed to the hexagonal lattice of $\mathrm{Mn}_{5} \mathrm{Ge}_{3}$. The pits can be classified in two groups (labelled 1 and 2 on the AFM images) according to their location on the surface and their profile (Fig. 6).

The first group consists of pits (labelled 1 on AFM images from Fig. 5) with a depth of tens of nanometres. The second group contains pits with a depth of only a few nanometres and with a flat bottom. Regarding the films growth under a Mn-rich co-deposition, the surface morphology appears more disturbed with lot of deep hexagonal holes, and still exhibits a fingers like morphology but with smaller features than the stoichiometric co-deposition case. Examining carefully the AFM $2 \times 2 \mu \mathrm{m}$ scans, terraces are visible with a height of $(0.45 \pm 0.05)$ $\mathrm{nm}$, which is still consistent with the step-flow growth detected by RHEED. The RMS roughness is around $2.2 \mathrm{~nm}$. To understand the evolution of the surface morphology, we have analyzed the distribution 

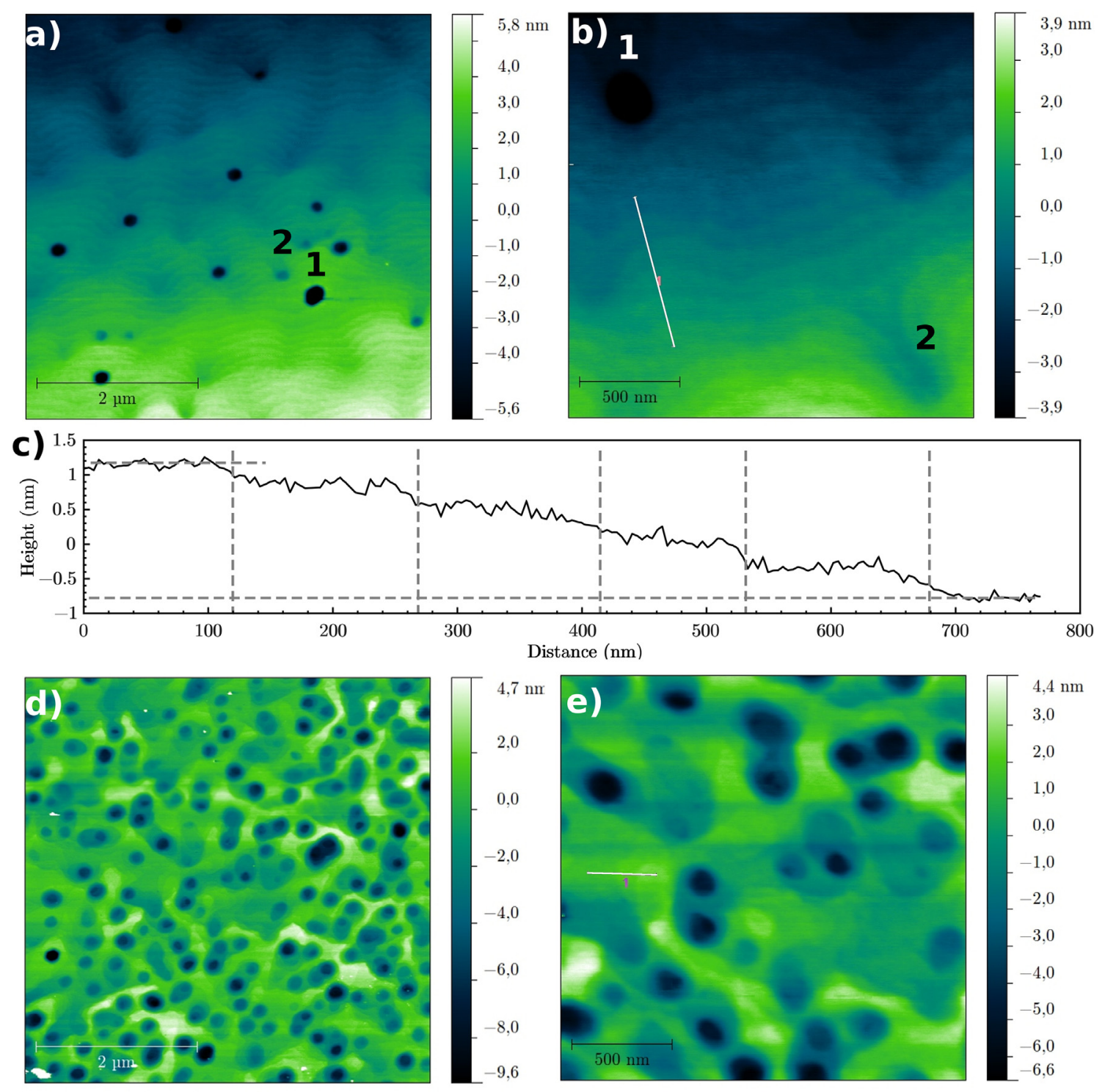

f) 2.6
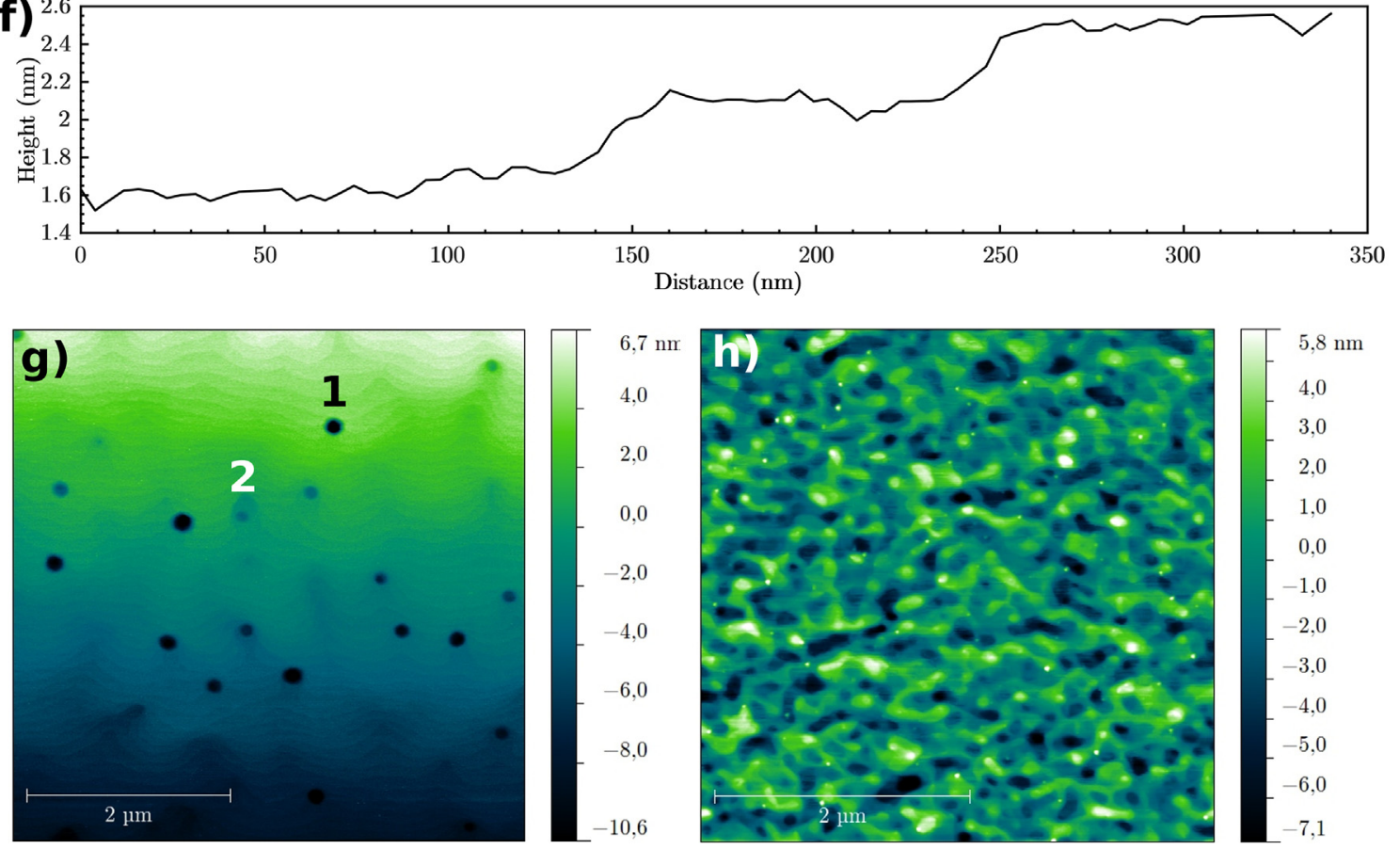


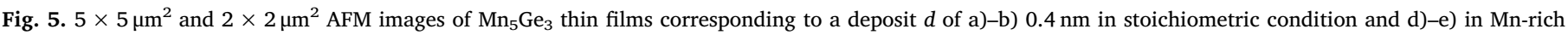

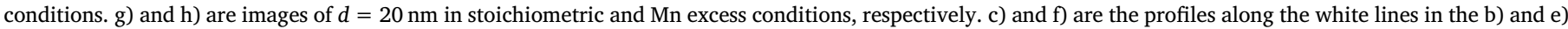
AFM scans. Labels 1 and 2 refer to two kinds of hexagonal pits observed on the surface.

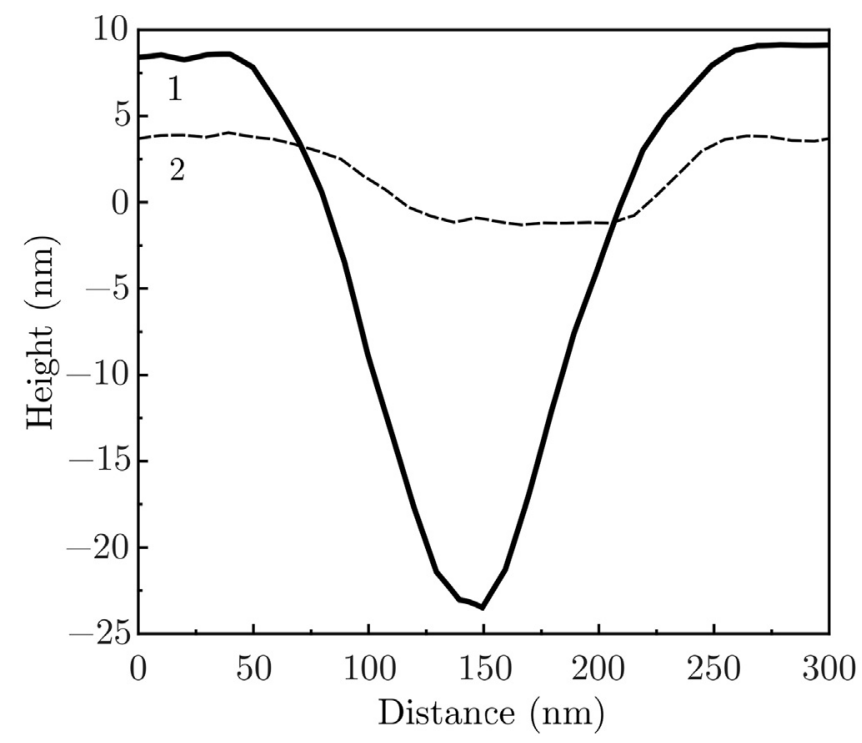

Fig. 6. Profiles from the hexagonal pits labelled 1 and 2 on the AFM images displayed on Fig. 5. Profile 1 corresponds to deep pits seemingly coming from the growth process and profile 2 corresponds to vacancy islands caused by selfcrossing steps. of the pits depth versus the thickness $d$ of the thin films (Fig. 7).

The distributions of the depths evolve with $d$ : at the very beginning of the deposit, the majority of the pits exhibits a depth in the sampling interval of $[-0.5 ;-1.5] \mathrm{nm}$ i.e in the range of the deposited thickness. Some holes already have a deeper depth around $-10 \mathrm{~nm}$. For $d=3.6 \mathrm{~nm}$, the distribution is bimodal: one part of the holes sampling presents a depth centred in the interval $[-3.5 ;-4.5] \mathrm{nm}$, and the second part consists of holes with a depth between -40 and $-50 \mathrm{~nm}$. As the deposition time increases, the depth distribution becomes once again mono-modal: the deepest pits disappear, and the majority of the depths is in the interval $[-0.5 ;-1.0] \mathrm{nm}$ for $d=20 \mathrm{~nm}$ : the pits may be filled during the growth. At this thickness, the pits density is $12.5 \mu \mathrm{m}^{-2}$ compared to $0.3 \mu \mathrm{m}^{-2}$ in the case of the stoichiometric codeposition.

Such pits were also observed in the case of GaN growth by MBE or plasma assisted MBE under Ga rich growth conditions [48,51,52]. The pits of group 2 have been described as vacancy islands caused by the self-crossing of the meandering steps, and which are not filled by the growth thereafter. These pits pin the steps and entail the fingers like morphology of the surface. Regarding the deeper holes of group 1, it seems unlikely that they can be related to dislocations or impurities: no dislocations (except interfacial ones) are observed in the TEM images of the $\mathrm{Mn}_{5} \mathrm{Ge}_{3}$ thin films, and the pits densities should be almost the same for both growth conditions if impurities were involved. So the group 1 may be also characteristic of the growth mode. This conclusion meets
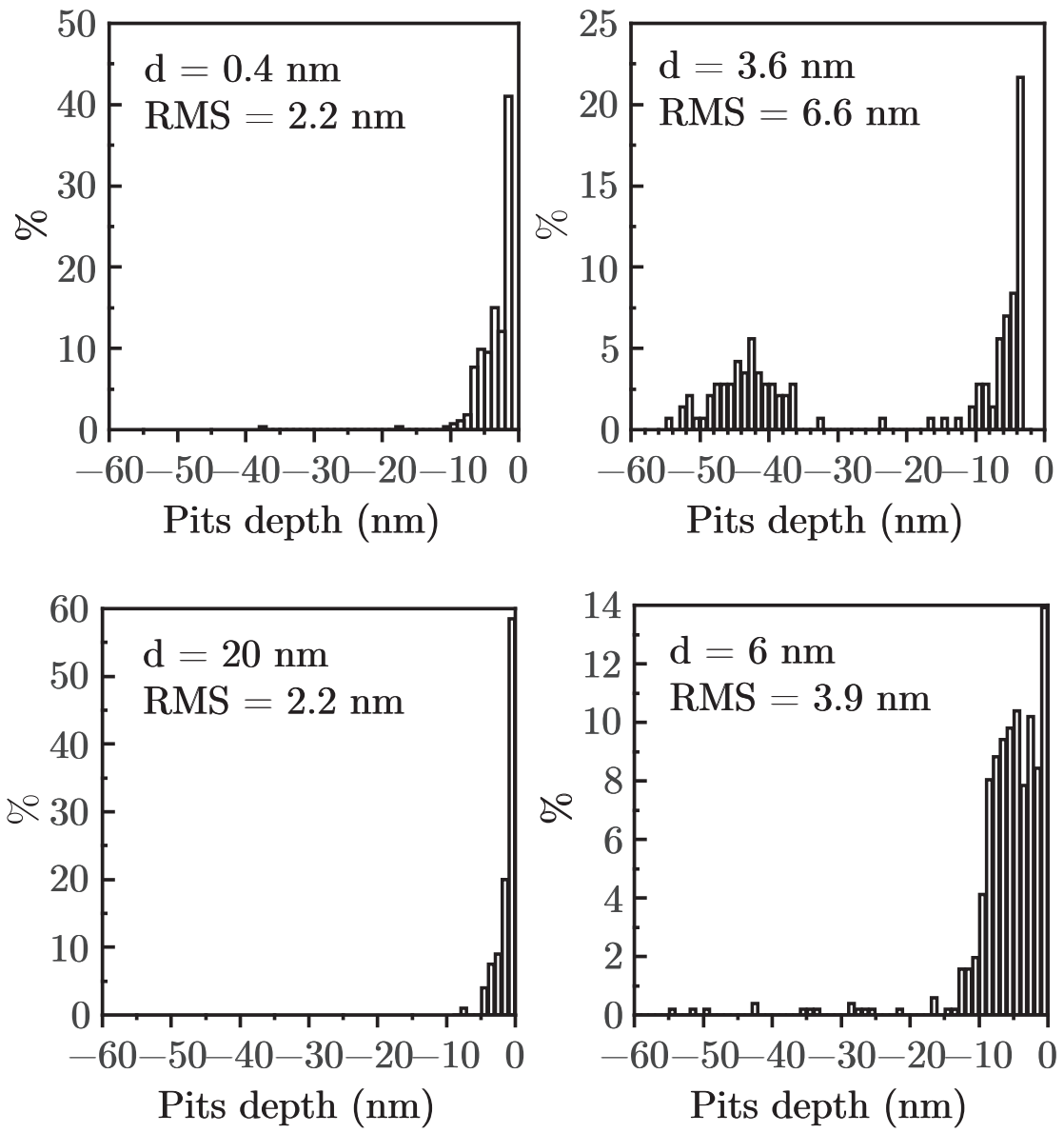

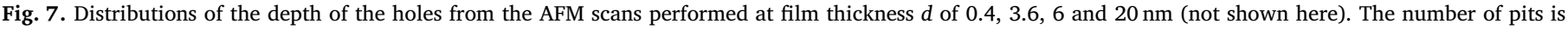
expressed in percentage of all the counted holes on each AFM images. The RMS roughness is reported for each deposition thickness. 
the one drawn by Chèze et al. regarding the growth of GaN films by plasma assisted MBE [51]. Another argument in favour of a characteristic of the growth mode comes from the other growth process of the $\mathrm{Mn}_{5} \mathrm{Ge}_{3}$ films, the SPE. Indeed, in the case of the SPE growth of manganese silicides and germanides, deep holes are also observed in the early stages of the thin films [37,53]. Hirvonen Grytzelius et al. have shown that an almost fully covering $\mathrm{Mn}_{5} \mathrm{Ge}_{3}$ film is obtained only after a deposition of 32 monolayers of $\mathrm{Mn}$, corresponding to a $\mathrm{Mn}_{5} \mathrm{Ge}_{3}$ thickness of $50 \mathrm{~nm}$. The holes are thought to play two main roles: local areas of strain relaxation of the thin films and complementary $\mathrm{Ge}$ sources for the formation of the $\mathrm{Mn}_{5} \mathrm{Ge}_{3}$ phase. This last point is consistent with our experiments where the pits density is higher in the case of a Mn-rich co-deposition. It means that to form the $\mathrm{Mn}_{5} \mathrm{Ge}_{3}$ phase, additional Ge atoms are drawn off in the substrate, thus creating deep holes.

\section{Conclusion}

A study of the early stages of the non-diffusive growth of $\mathrm{Mn}_{5} \mathrm{Ge}_{3}$ thin film on Ge(111) substrate has been carried out. This system exhibits a significant lattice mismatch of $3.7 \%$. XRD measurements demonstrate that the thin film is monocrystalline and, combined with RHEED diffraction patterns analysis, that the $\mathrm{Mn}_{5} \mathrm{Ge}_{3}$ lattice is slightly strained. TEM images show the presence of interfacial dislocations at the $\mathrm{Mn}_{5} \mathrm{Ge}_{3} / \mathrm{Ge}$ interface, every $16 \mathrm{~nm}$ along the [010] direction of the $\mathrm{Mn}_{5} \mathrm{Ge}_{3}$ film. Thus, the lattice mismatch is accommodated by two phenomena: a pseudomorphic growth and interfacial dislocations. Numerical calculations support these observations: the critical nucleation volumes calculated for both the case of a pseudomorphic growth and the case of an accommodation of the lattice mismatch by an array of dislocations, are very similar in values. AFM images taken at different deposition times and the evolution of the specular RHEED intensity, both recorded in stoichiometric and Mn-rich co-deposition conditions, show that the $\mathrm{Mn}_{5} \mathrm{Ge}_{3}$ films grow according to a step-flow mode, with a meandering instability.

\section{Acknowledgments}

The authors would like to thank D Chaudanson from the electron microscopes service of the CINaM for his support regarding the TEM images and C Coudreau for the technical support on the MBE growth set-up.

\section{Appendix A. Supplementary data}

Supplementary data to this article can be found online at https:// doi.org/10.1016/j.apsusc.2019.01.164.

\section{References}

[1] R. Duine, Spintronics: an alternating alternative, Nat. Mater. 10 (5) (2011) 344-345, https://doi.org/10.1038/nmat3015 http://www.nature.com/doifinder/ 10.1038/nmat3015\{\%\}5Cnpapers2://publication/doi/10.1038/nmat3015.

[2] H. Ohno, M.D. Stiles, Dieny Bernard, Advancements in spintronics, Solid State Technology 60 (6) (2017) 22-27 http://electroiq.com/blog/2017/09/ advancements-in-spintronics/.

[3] K.Y. Ahn, M.W. Shafer, Relationship between stoichiometry and properties of EuO films, Journal of Applied Physics 00218979, 41 (3) (1970) 1260-1262, https://doi. org/10.1063/1.1658902.

[4] S. Von Molnár, D. Read, New materials for semiconductor spin-electronics, Proceedings of the IEEE 00189219, 91 (5) (2003) 715-726, https://doi.org/10. 1109/JPROC. 2003.811803.

[5] H. Ohno, Making nonmagnetic semiconductors ferromagnetic, Science 1095-9203, 281 (5379) (1998) 951-956, https://doi.org/10.1126/science.281.5379.951 http://www.sciencemag.org/cgi/doi/10.1126/science.281.5379.951.

[6] L. Morresi, J. Ayoub, N. Pinto, M. Ficcadenti, R. Murri, a. Ronda, I. Berbezier, F. D'Orazio, F. Lucari, Structural, magnetic and electronic transport properties of $\mathrm{Mn}_{x} \mathrm{Ge}_{1 x} / \mathrm{Ge}(001)$ films grown by MBE at 350C, Surface Science 00396028, 601 (13) (2007) 2632-2635, https://doi.org/10.1016/j.susc. 2006.11.077 http:// linkinghub.elsevier.com/retrieve/pii/S0039602806012490.
[7] E. Arras, D. Caliste, T. Deutsch, F. Lançon, P. Pochet, Phase diagram, structure, and magnetic properties of the Ge-Mn system: a first-principles study, Physical Review B 1098-0121, 83 (17) (2011) 1-12, https://doi.org/10.1103/PhysRevB.83.174103.

[8] L. Chen, X. Yang, F. Yang, J. Zhao, J. Misuraca, P. Xiong, S. Von Molnár, Enhancing the curie temperature of ferromagnetic semiconductor (Ga,Mn)As to $200 \mathrm{~K}$ via nanostructure engineering, Nano Letters 15306984, 11 (7) (2011) 2584-2589, https://doi.org/10.1021/nl201187m.

[9] M. Aouassa, M.A. Zrirb, I. Jadli, A.K. Bandyopadhyay, I. Karaman, G. Panczer, $\mathrm{H}$. Maaref, Mn-doping effects on structural and magnetic properties of Ge nanocrystals on insulator, Applied Surface Science 01694332, 428 (2018) 1056-1060, https://doi.org/10.1016/j.apsusc.2016.11.087.

[10] C. Zeng, S.C. Erwin, L.C. Feldman, A.P. Li, R. Jin, Y. Song, J.R. Thompson, H.H. Weitering, Epitaxial ferromagnetic $\mathrm{Mn}_{5} \mathrm{Ge}_{3}$ on $\mathrm{Ge}(111)$, Applied Physics Letters 83 (24) (2003) 5002-5004, https://doi.org/10.1063/1.1633684 http://link. aip.org/link/?APL/83/5002/1.

[11] F. Hellman, A. Hoffmann, Y. Tserkovnyak, G.S.D. Beach, E.E. Fullerton, C. Leighton, A.H. MacDonald, D.C. Ralph, D.A. Arena, H.A. Dürr, P. Fischer, J. Grollier, J.P. Heremans, T. Jungwirth, A.V. Kimel, B. Koopmans, I.N. Krivorotov, S.J. May, A.K. Petford-Long, J.M. Rondinelli, N. Samarth, I.K. Schuller, A.N. Slavin, M.D. Stiles, O. Tchernyshyov, A. Thiaville, B.L. Zink, Interface-induced phenomena in magnetism, Reviews of Modern Physics 0034-6861, 89 (2) (2017) 25006, https://doi.org/10.1103/RevModPhys.89.025006 arXiv:1607.00439.

[12] Y. Tawara, K. Sato, On the magnetic anisotropy of single crystal of $\mathrm{Mn}_{5} \mathrm{Ge}_{3}$, Journal of Physical Society of Japan 18 (1963) 773-777, https://doi.org/10.1143/JPSJ.18. 773.

[13] M. Gajdzik, C. Sürgers, M.T. Kelemen, H. v. Löhneysen, Strongly enhanced Curie temperature in carbon-doped $\mathrm{Mn}_{5} \mathrm{Ge}_{3}$ films, Journal of Magnetism and Magnetic Materials 0304-8853, 221 (3) (2000) 248-254, https://doi.org/10.1016/S0304. 8853(00)00494-7 http://www.sciencedirect.com/science/article/pii/ S0304885300004947.

[14] I. Slipukhina, E. Arras, P. Mavropoulos, P. Pochet, Simulation of the enhanced Curie temperature in $\mathrm{Mn}_{5} \mathrm{Ge}_{3} \mathrm{C}_{x}$ compounds, Applied Physics Letters 00036951, 94 (19) (2009) 192505, https://doi.org/10.1063/1.3134482 arXiv:0902.2913, http:// arxiv.org/abs/0902.2913 http://link.aip.org/link/APPLAB/v94/i19/p192505/s $\& A g g=$ doi http://link.aip.org/link/?APL/94/192505/1.

[15] S. Picozzi, A. Continenza, A.J. Freeman, First-principles characterization of ferromagnetic $\mathrm{Mn}_{5} \mathrm{Ge}_{3}$ for spintronic applications, Phys. Rev. B 235205 (70) (2004) 235205-235210, https://doi.org/10.1103/PhysRevB.70.235205.

[16] Y.S. Dedkov, M. Holder, G. Mayer, M. Fonin, A.B. Preobrajenski, Spin-resolved photoemission of a ferromagnetic $\mathrm{Mn}_{5} \mathrm{Ge}_{3}(0001)$ epilayer on $\mathrm{Ge}(111)$, Journal of Applied Physics 105 (7) (2009) 073909, https://doi.org/10.1063/1.3103336 http://scitation.aip.org/content/aip/journal/jap/105/7/10.1063/1.3103336.

[17] L.-A. Michez, A. Spiesser, M. Petit, S. Bertaina, J.-f. Jacquot, D. Dufeu, C. Coudreau, M. Jamet, V.L. Thanh, Magnetic reversal in $\mathrm{Mn}_{5} \mathrm{Ge}_{3}$ thin films: an extensive study, Journal of Physics: Condensed Matter 0953-8984, 27 (2015) 266001, https://doi. org/10.1088/0953-8984/27/26/266001.

[18] J.D. Albrecht, D.L. Smith, Spin-polarized electron transport at ferromagnet-semiconductor Schottky contacts, Physical Review B 68 (2003) 35340, https://doi.org/ 10.1103/PhysRevB.68.035340.

[19] E. Arras, Étude théorique de la structure et de la stabilité des alliages GeMn dans le cadre de la spintronique. Un prototype de semiconducteur magnétique confronté aux résultats expérimentaux, Ph.D. thesis Université Joseph-Fourier - Grenoble I, 2010, https://tel.archives-ouvertes.fr/tel-00489879v2.

[20] A. Berche, J.C. Tedenac, P. Jund, Thermodynamic modeling of the germaniummanganese system, Intermetallics 09669795, 47 (2014) 23-30, https://doi.org/10. 1016/j.intermet.2013.12.009.

[21] M. Petit, L. Michez, C.-E. Dutoit, S. Bertaina, V.O. Dolocan, V. Heresanu, M. Stoffel, V. Le Thanh, Very low-temperature epitaxial growth of $\mathrm{Mn}_{5} \mathrm{Ge}_{3}$ and $\mathrm{Mn}_{5} \mathrm{Ge}_{3} \mathrm{C}_{0 .}$ films on $\mathrm{Ge}(111)$ using molecular beam epitaxy, Thin Solid Films 00406090, 589 (2015) 427-432, https://doi.org/10.1016/j.tsf.2015.05.068 http://linkinghub. elsevier.com/retrieve/pii/S0040609015006057.

[22] M. Petit, R. Hayakawa, Y. Wakayama, V.L. Thanh, L. Michez, V. Le Thanh, L. Michez, $\mathrm{Mn}_{5} \mathrm{Ge}_{3} \mathrm{C}_{0.6} / \mathrm{Ge}(111)$ Schottky contacts tuned by an $\mathrm{n}$-type ultra-shallow doping layer, Journal of Physics D: Applied Physics 0022-3727, 49 (35) (2016) 355101, https://doi.org/10.1088/0022-3727/49/35/355101 http://stacks.iop. org $/ 0022-3727 / 49 / \mathrm{i}=35 / \mathrm{a}=355101$ ? $\mathrm{key}=$ crossref 6a1b790cc253d129a5b6c07675393822.

[23] S.F. Olive-Mendez, A. Spiesser, L.A. Michez, V. Le Thanh, A. Glachant, J. Derrien, T. Devillers, A. Barski, M. Jamet, Epitaxial growth of $\mathrm{Mn}_{5} \mathrm{Ge}_{3} / \mathrm{Ge}(111)$ heterostructures for spin injection, Thin Solid Films 0040-6090, 517 (1) (2008) 191-196, https://doi.org/10.1016/j.tsf.2008.08.090 http://www.sciencedirect.com/science/ article/pii/S0040609008009176.

[24] D. Nečas, P. Klapetek, Gwyddion: an open-source software for SPM data analysis, Central European Journal of Physics 10 (1) (2012) 181-188, https://doi.org/10. 2478/s11534-011-0096-2.

[25] J.W. Matthews, A.E. Blakeslee, Defects in epitaxial multilayers: I. Misfit dislocations, Journal of Crystal Growth 27 (1974) 118-125, https://doi.org/10.1016/ S0022-0248(74)80055-2.

[26] J.W. Matthews, Defects associated with the accommodation of misfit between crystals, Journal of Vacuum Science \& Technology 12 (1) (1975) 126-133, https:// doi.org/10.1116/1.568741.

[27] I. Markov, Recent theoretical developments in epitaxy, Materials Chemistry and Physics 36 (1-2) (1993) 1-30, https://doi.org/10.1016/0254-0584(93)90002-4.

[28] G. Saint-Girons, J. Cheng, P. Regreny, L. Largeau, G. Patriarche, G. Hollinger, Accommodation at the interface of highly dissimilar semiconductor/oxide epitaxial systems, Physical Review B 1098-0121, 80 (15) (2009) 155308, https://doi.org/10. 
1103/PhysRevB.80.155308.

[29] K. Tillmann, A. Forster, Critical dimensions for the formation of interfacial misfit dislocations of $\mathrm{In}_{0.6} \mathrm{Ga}_{0.4}$ As islands on GaAs(001), Thin Solid Films 368 (1) (2000) 93-104, https://doi.org/10.1016/S0040-6090(00)00858-0.

[30] T. Irisawa, A. Ichimiya, T. Kuroda, Periodic changes in the structure of a surface growing under MBE conditions and RHEED oscillation, Surface Science 00396028 , 242 (1-3) (1991) 148-151, https://doi.org/10.1016/0039-6028(91)90257-S.

[31] L.E. Vorobyev, Germanium (Ge), in: M. Levinshtein, S. Rumyantsev, M. Shur (Eds.), Handbook Series on Semiconductor Parameters, 1 World Scientific, 1996, pp. 33-57, , https://doi.org/10.1142/9789812832078_0002 978-981-02-2934-4.

[32] M.E. Fine, Elasticity and thermal expansion of germanium between -195 and $275^{\circ} \mathrm{C}$, Journal of Applied Physics 00218979, 24 (3) (1953) 338-340, https://doi. org/10.1063/1.1721275.

[33] J.J. Wortman, R.A. Evans, Young's modulus, shear modulus, and Poisson's ratio in silicon and germanium, Journal of Applied Physics 00218979, 36 (1) (1965) 153-156, https://doi.org/10.1063/1.1713863 arXiv:1011.1669v3.

[34] Z.A. Istomina, G.P. Zinoveva, L.P. Andreeva, P.V. Geld, A. Mikhelson, Elastic characteristics of $\mathrm{Mn}_{5} \mathrm{Si}_{3}$ in the temperature range 20-400 K, Fizika Tverdogo Tela 22 (1) (1980) 281-283.

[35] R.J. Jaccodine, Surface energy of germanium and silicon, Journal of the Electrochemical Society 00134651, 110 (6) (1963) 524, https://doi.org/10.1149/1. 2425806 http://jes.ecsdl.org/cgi/doi/10.1149/1.2425806.

[36] P.G. Partridge, The crystallography and deformation modes of hexagonal closepacked metals, Metallurgical Reviews 12 (1967) 169-194, https://doi.org/10. 1179/mtlr.1967.12.1.169.

[37] J. Hirvonen Grytzelius, H.M. Zhang, L.S.O. Johansson, $\mathrm{Mn}_{5} \mathrm{Ge}_{3}$ film formation on $\mathrm{Ge}(111) \mathrm{c}(2 \times 8)$, Physical Review B - Condensed Matter and Materials Physics 10980121, 86 (12) (2012) 125313, https://doi.org/10.1103/PhysRevB.86.125313.

[38] C. Zeng, W. Zhu, S.C. Erwin, Z. Zhang, H.H. Weitering, Initial stages of Mn adsorption on Ge(111), Physical Review B 1098-0121, 70 (20) (2004) 2-9, https:// doi.org/10.1103/PhysRevB.70.205340 http://link.aps.org/doi/10.1103/ PhysRevB.70.205340.

[39] B.J. Keene, Review of data for the surface tension of pure metals, International Materials Reviews 0950-6608, 38 (4) (1993) 157-192, https://doi.org/10.1179/ imr.1993.38.4.157 http://www.tandfonline.com/doi/full/10.1179/imr.1993.38.4. 157.

[40] M. Aldén, H.L. Skriver, S. Mirbt, B. Johansson, Surface energy and magnetism of the 3d metals, Surface Science 00396028, 315 (1-2) (1994) 157-172, https://doi.org/ 10.1016/0039-6028(94)90551-7.

[41] L. Vitos, A.V. Ruban, H.L. Skriver, J. Kollár, The surface energy of metals, Surface Science 411 (1-2) (1998) 186-202, https://doi.org/10.1016/S0039-6028(98) 00363-X.

[42] R. Tran, Z. Xu, B. Radhakrishnan, D. Winston, W. Sun, K.A. Persson, S.P. Ong,
Surface energies of elemental crystals, Scientific Data 14765500, 3:160080 (2016), https://doi.org/10.1038/sdata.2016.80.

[43] G.N. Greaves, Poisson's ratio over two centuries: challenging hypotheses, Notes Rec. R. Soc. 67 (2013) 37-58, https://doi.org/10.1098/rsnr.2012.0021.

[44] A.T. D'Agostino, Determination of thin metal film thickness by X-ray diffractometry using the Scherrer equation, atomic absorption analysis and transmission/reflection visible spectroscopy, Analytica Chimica Acta 00032670, 262 (2) (1992) 269-275, https://doi.org/10.1016/0003-2670(92)80064-E.

[45] P. De Padova, J.M. Mariot, L. Favre, I. Berbezier, B. Olivieri, P. Perfetti, C. Quaresima, C. Ottaviani, a. Taleb-Ibrahimi, P. Le Fèvre, F. Bertran, O. Heckmann, M.C. Richter, W. Ndiaye, F. D'Orazio, F. Lucari, C.M. Cacho, K. Hricovini, $\mathrm{Mn}_{5} \mathrm{Ge}_{3}$ films grown on Ge(1 11 1)-c(2 × 8), Surface Science 00396028, 605 (5-6) (2011) 638-643, https://doi.org/10.1016/j.susc.2011.01.002.

[46] A. Spiesser, H. Saito, R. Jansen, S. Yuasa, K. Ando, Large spin accumulation voltages in epitaxial $\mathrm{Mn}_{5} \mathrm{Ge}_{3}$ contacts on Ge without an oxide tunnel barrier Aur, Physical Review B 1098-0121, 90 (20) (2014) 205213, https://doi.org/10.1103/PhysRevB. 90.205213 http://link.aps.org/doi/10.1103/PhysRevB.90.205213.

[47] J.H. Neave, P.J. Dobson, B.A. Joyce, J. Zhang, Reflection high-energy electron diffraction oscillations from vicinal surfaces - a new approach to surface diffusion measurements, Applied Physics Letters 00036951, 47 (2) (1985) 100-102, https:// doi.org/10.1063/1.96281.

[48] C. Adelmann, J. Brault, D. Jalabert, P. Gentile, H. Mariette, G. Mula, B. Daudin, Dynamically stable gallium surface coverages during plasma-assisted molecularbeam epitaxy of (0001) GaN, Journal of Applied Physics 00218979, 91 (12) (2002) 9638-9645, https://doi.org/10.1063/1.1471923.

[49] J. Kallunki, J. Krug, Breakdown of step flow growth in unstable homoepitaxy, Europhysics Letters 02955075, 66 (5) (2004) 749-755, https://doi.org/10.1209/ epl/i2004-10026-8.

[50] C. Misbah, O. Pierre-Louis, Y. Saito, Crystal surfaces in and out of equilibrium: a modern view, Reviews of Modern Physics 00346861, 82 (1) (2010) 981-1040, https://doi.org/10.1103/RevModPhys.82.981.

[51] C. Chèze, M. Sawicka, M. Siekacz, H. Turski, G. Cywiński, J. Smalc-Koziorowska, J.L. Weyher, M. Kryśko, B. Łucznik, M. Boćkowski, C. Skierbiszewski, Step-flow growth mode instability of N-polar GaN under N-excess, Applied Physics Letters 00036951, 103 (7) (2013), https://doi.org/10.1063/1.4818322.

[52] E.J. Tarsa, B. Heying, X.H. Wu, P. Fini, S.P. DenBaars, J.S. Speck, Homoepitaxial growth of GaN under Ga-stable and N-stable conditions by plasma-assisted molecular beam epitaxy, Journal of Applied Physics 00218979, 82 (11) (1997) 5472-5479, https://doi.org/10.1063/1.365575.

[53] A. Kumar, M. Tallarida, M. Hansmann, U. Starke, K. Horn, Thin manganese films on Si(111)-(7 × 7): electronic structure and strain in silicide formation, Journal of Physics D: Applied Physics 00223727, 37 (7) (2004) 1083-1090, https://doi.org/ 10.1088/0022-3727/37/7/021. 